\title{
Chromosome number of myoga ginger (Zingiber mioga: Zingiberaceae) in Korea
}

\author{
Hiroshi IKEDA*, Bo-Mi NAM', Nobuko YAMAMOTO², Hidenobu FUNAKOSHI ${ }^{3}$, \\ Atsuko TAKANO ${ }^{4}$ and Hyoung-Tak IM ${ }^{5}$ \\ The University Museum, The University of Tokyo, Tokyo 113-0033, Japan \\ ${ }^{1}$ International Biological Material Research Center, Korea Research Institute of Bioscience \& Biotechnology, Daejeon 34141, Korea \\ ${ }^{2}$ Natural History Museum and Institute, Chiba 260-0852, Japan \\ ${ }^{3}$ Botanical Research Institute of Chiba, Chiba 290-0053, Japan \\ ${ }^{4}$ Museum of Nature and Human Activities, Hyogo 669-1546, Japan \\ ${ }^{5}$ Department of Biological Sciences, Chonnam National University, Gwangju 61186, Korea
}

(Received 2 February 2021; Revised 11 March 2021; Accepted 12 March 2021)

\begin{abstract}
The chromosome number of myoga ginger (Zingiber mioga (Thunb.) Roscoe: Zingiberaceae) has been reported as $2 n=22$ for Chinese plants and $2 n=55$ for Japanese plants. We checked the chromosome number of Z. mioga in plants collected in Jeollabuk-do and Jeollanam-do, Korea, and counted $2 n=44$, the first report of this number for the species. As the basic chromosome number of $Z$. mioga is thought to be $x=11, Z$. mioga plants in China, Korea, and Japan appear to be diploids, tetraploids, and pentaploids, respectively. In finding the tetraploid race of Z. mioga in Korea, we can hypothesize that the pentaploid race in Japan is derived through the fertilization of reduced gametes of the diploid race and unreduced gametes of the tetraploid race.

Keywords: chromosome number, edible plant, Korea, myoga ginger, tetraploid, Zingiber mioga, Zingiberaceae
\end{abstract}

Myoga ginger (Zingiber mioga (Thunb.) Roscoe: Zingiberaceae) is a perennial herb, native to tropical Asia (Makino et al., 1961). It is cultivated for its edible flowers (inflorescences) in Japan and edible and medicinal use in China (Wu and Larsen, 2000; Ohba 2016). In Korea, however, it is only occasionally cultivated, and naturalized, mainly on the southern peninsula and on Jeju Island (Lee, 1996, 2006; Jung et al., 2016; Korea National Arboretum, 2016; Kim and Kil, 2016).

The chromosome number of $Z$. mioga has been reported to be $2 n=55$ in Japanese plants (Morinaga et al., 1929; Takenaka, 1932; Sato, 1960; Suzuka and Mitsuoka, 1968) while $2 n=22$ has been reported for the species in China (Chen et al., 1982). As the basic chromosome number of Z. mioga may be $x=11$, the plants in Japan are pentaploids, while those in China are diploids. We were therefore intrigued to know the ploidy level of Z. mioga in Korea, an area between the diploid and pentaploid races.

\section{Materials and Methods}

We collected plants of $Z$. mioga at two localities in Korea and transplanted them to the nurseries of the Korea Research Institute of Bioscience \& Biotechnology (Daejeon, Korea) and to the University of Tokyo (Tokyo, Japan) to be used for cytological investigation (Table 1).

Root tips were pretreated with a $2 \mathrm{mM}$ 8-hydroxyquinoline solution at $20^{\circ} \mathrm{C}$ for $1 \mathrm{~h}$ and consequently at $4^{\circ} \mathrm{C}$ for $15 \mathrm{~h}$ before being fixed with Newcomer's fluid (see Sharma and Sharma, 1980). Fixed root tips were macerated in $1 \mathrm{~N} \mathrm{HCl}$ for $10 \mathrm{~min}$ at $60^{\circ} \mathrm{C}$. After washing with distilled water, they were stained with $2 \%$ lacto-propionic orcein. Slide preparations were made by the conventional squash method.

\section{Results and Discussion}

The chromosomes of Z. mioga in Korea were counted as

\footnotetext{
*Author for correspondence: h_ikeda@um.u-tokyo.ac.jp
} 
Table 1. List of voucher specimens for this study.

\begin{tabular}{cc}
\hline \hline Locality & Collection no. (Herbarium) \\
\hline Korea. Jeollabuk-do, Jeonju-si, Haksan Mt. & B.-M. Nam 200926ZM01 (KRIB) \\
Korea. Jeollanam-do, Muan-gun, Mongtan-myeon, Dalsan-ri, Beopcheon-sa Temple & $H$. Ikeda 18101801 (TI) \\
\hline
\end{tabular}
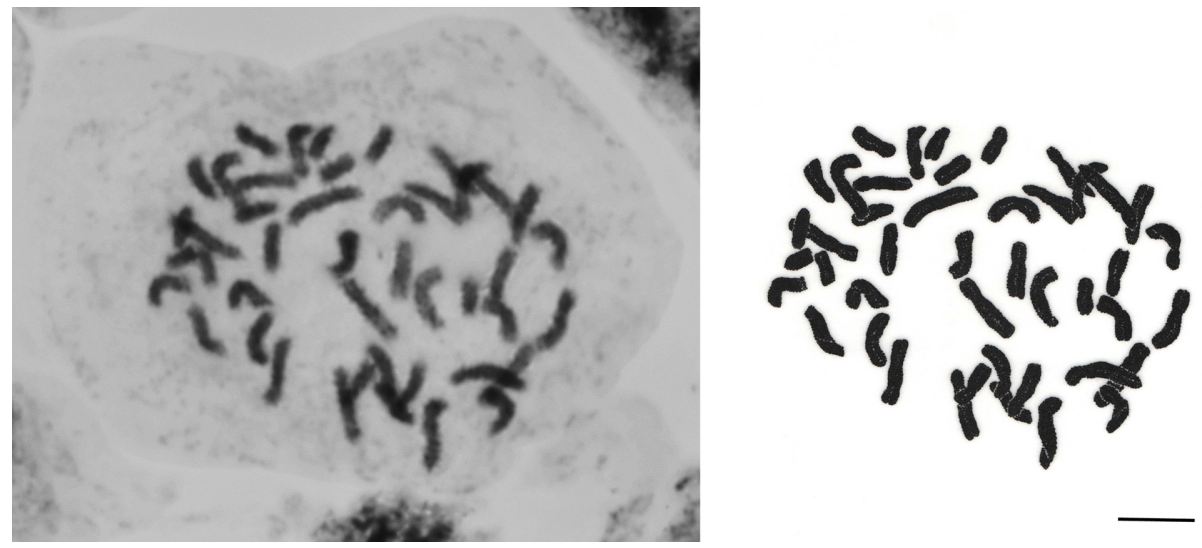

Fig. 1. Photomicrograph (left) and drawing (right) of somatic chromosomes of Zingiber mioga from Korea $(2 n=44)$. Scale bar $=5 \mu \mathrm{m}$.

$2 n=44$ (Fig. 1). Counts of $2 n=22$ (Chen et al., 1982) and $2 n=55$ (Morinaga et al., 1929; Takenaka, 1932; Sato 1960; Suzuka and Mitsuoka, 1968) have been reported for $Z$ mioga. The report of $2 n=44$ is therefore the first for this species. As the basic chromosome number of Z. mioga is thought to be $x$ $=11,2 n=44$ for Z. mioga in Korea may be a tetraploid.

Polyploidization plays an important role in the diversification of plants (Grant, 1981; Soltis and Soltis, 2009; Soltis et al., 2009), and also impacts crop domestication and establishment of important agronomic traits (Hancock, 2005; Renny-Byfield and Wendel, 2014; Zhang et al., 2019). Therefore, Z. mioga is thought to have been improved through polyploidization from the diploid race in China to a pentaploid race in Japan. It has been difficult, however, to explain the process of establishment of pentaploids directly from diploids, since additional steps are needed in the polyploidization process. In finding the tetraploid race of Z. mioga in Korea, we can hypothesize that the pentaploid race is derived through fertilization of reduced gametes of the diploid race and unreduced gametes of the tetraploid race. Although it is just a hypothesis, we may be able to clarify the process of the establishment of the pentaploid race of $Z$. mioga through further cytological and molecular investigations of these cytotypes.

ORCID: Hiroshi IKEDA https://orcid.org/0000-0001-81305129; Bo-Mi NAM https://orcid.org/0000-0002-6769-9317; Nobuko YAMAMOTO https://orcid.org/0000-0002-0227-991X;
Hidenobu FUNAKOSHI https://orcid.org/0000-0003-45777158; Atsuko TAKANO https://orcid.org/0000-0002-83455080; Hyoung-Tak IM https://orcid.org/0000-0002-6333-6244

\section{Acknowledgments}

We appreciate Dr. David E. Boufford, Harvard University, for checking the English manuscript. This study was partly supported by JSPS KAKENHI Grant Number 17K07527 for H.I.

\section{Conflict of Interest}

The authors declare that there are no conflicts of interest.

\section{Literature Cited}

Chen, Z.-Y., S.-J. Chen and S.-F. Hwang. 1982. Preliminary report of chromosome numbers on Chinese Zingiberaceae. Guihaia 2: 153-157. (in Chinese)

Grant, V. 1981. Plant Speciation. 2nd ed. Columbia University Press, New York, 563 pp.

Hancock, J. F. 2005. Contributions of domesticated plant studies to our understanding of plant evolution. Annals of Botany 96 : 953-963.

Jung, S. Y., J. W. Lee, Y. H. Kwon, H. T. Shin, S. J. Kim, J. B. An and T. I. Heo. 2016. Invasive Alien Plants in South Korea. 
Korea National Arboretum, Pocheon, 265 pp. (in Korean)

Kim, C.-G. and J. Kil. 2016. Alien flora of the Korean Peninsula. Biological Invasions 18: 1843-1852.

Korea National Arboretum. 2016. Distribution Maps of Vascular Plants in Korea. Korea National Arboretum, Pocheon, 809 pp.

Lee, Y. N. 1996. Flora of Korea. Kyo-Hak Publishing, Seoul, 1247 pp. (in Korean)

Lee, Y. N. 2006. New Flora of Korea, Vol. 2. Kyo-Hak Publishing, Seoul, 885 pp. (in Korean)

Makino, T., F. Maekawa, H. Hara and T. Tuyama. 1961. Makino's New Illustrated Flora of Japan. Rev. ed. Hokuryukan, Tokyo, 1057 pp. (in Japanese)

Morinaga, T., E. Fukushima, T. Kano, Y. Maruyama and Y. Yamasaki. 1929. Chromosome numbers of cultivated plants. II. Botanical Magazine (Tokyo) 43: 589-594.

Ohba, H. 2016. Zingiberaceae. In Flora of Japan, Vol. IVb. Angiospermae Monocotyledoneae. Iwatsuki, K., D. E. Boufford and H. Ohba (eds.), Kodansha, Tokyo. Pp. 187-191.

Renny-Byfield, S. and J. F. Wendel. 2014. Doubling down on genomes: polyploidy and crop plants. American Journal of Botany 101: 1711-1725.

Sato, D. 1960. The karyotype analysis in Zingiberales with special reference to the protokaryotype and stable karyotype. Science Papers of the College of General Education, University of Tokyo 10: 225-243.
Sharma, A. K. and A. Sharma. 1980. Chromosome Techniques: Theory and Practice. 3rd ed. Butterworths-Heinemann, London. P. 55.

Soltis, D. E., V. A. Albert, J. Leebens-Mack, C. D. Bell, A. H. Paterson, C. Zheng, D. Sankoff, C. W. de Pamphilis, P. K. Wall and P. S. Soltis. 2009. Polyploidy and angiosperm diversification. American Journal of Botany 96: 336-348.

Soltis, P. S. and D. E. Soltis. 2009. The role of hybridization in plant speciation. Annual Review of Plant Biology 60: 561588.

Suzuka, O. and S. Mitsuoka. 1968. Zingiber mioga Roscoe, a sterile plant. Report of Kihara Institute for Biological Research 20: 103-107.

Takenaka, Y. 1932. Further reports of the cytological investigations on the sterile plants. V. On the chromosome of Zingiber mioga Roscoe. Journal of Chosen Natural History Society 13 : $25-41$.

Wu, T.-L. and K. Larsen. 2000. Zingiberaceae. In Flora of China, Vol. 24. Flagellariaceae through Marantaceae. Wu, Z.-Y. and P. H. Raven (eds.), Science Press, Beijing and Missourie Botanical Garden, St. Louis, MO. Pp. 322-377.

Zhang, K., X. Wang and F. Cheng. 2019. Plant polyploidy: origin, evolution, and its influence on crop domestication. Horticultural Plant Journal 5: 231-239. 